\title{
Group Decision Support Approach for Cloud Quality of Service Criteria Weighting
}

\author{
Constanţa Zoie RADULESCU ${ }^{1 *}$, Marius RADULESC ${ }^{2}$ \\ ${ }^{1}$ National Institute for Research and Development in Informatics, 8-10, Averescu Avenue, \\ Bucharest, 01145, Romania \\ radulescucz@yahoo.com, zoie.radulescu@ici.ro (*Corresponding author) \\ ${ }^{2}$ Institute of Mathematical Statistics and Applied Mathematics, Calea 13 Septembrie, No.13, \\ Bucharest, 050711, Romania \\ mradulescu.csmro@yahoo.com
}

\begin{abstract}
A decision to select a Cloud Services Provider (CSP), taking into account the user requirements is a multi-criteria problem. The Multi-Criteria Decision Making (MCDM) methods can be of real help in solving this problem. The most critical input of MCDM methods is the assignment of criteria weights. This paper provides a synthesis of criteria weighting methods and proposed a new Group Decision Support approach for Quality of Service (QoS) criteria analysis and weighting. The approach is based on a hybrid method which is a combination of a subjective weighting method - Decision-Making Trial and Evaluation Laboratory (DEMATEL) method and an objective weighting method - Shannon method. Based on cloud experts' evaluation of influential relationships between the criteria, the first QoS criteria weights are calculated with DEMATEL method. Then, based on the decision matrix of CSPs evaluated by QoS criteria, the QoS criteria weights are calculated with Shannon method. The final weights of QoS criteria, a combination of DEMATEL weights and Shannon weights, are obtained. The Group Decision Support approach proposed is applied in a case study. An analysis of causal relations and the degree of influence between QoS criteria based on cloud computing experts' evaluation and DEMATEL method is presented.
\end{abstract}

Keywords: Criteria weighting methods, Cloud Computing, Quality of Service criteria, Group Decision Support, DEMATEL method, Shannon method.

\section{Introduction}

The adoption of Cloud Computing by organizations has increased exponentially in recent years, being a basic catalyst for the transition to the digital era. Generally cloud architecture delivers three main services: Infrastructure as a Service (IaaS), Platform as a Service (PaaS) and Software as a Service (SaaS), according to the requirements of the user. The services are made available by the Cloud Services Providers (CSPs) with a variety of Quality of Service (QoS) attributes (criteria).

Several approaches for ranking and selection of CSP were studied in the literature. One of these approaches is based on the Multi Criteria Decision Making (MCDM). In the MCDM problem the alternatives are the CSPs and the criteria are the QoS criteria. The MCDM methods can be of real help in selecting a CSP by taking into account the user requirements.

For the analysis of the benefits and risks in adopting a CSP the analysis of QoS metrics plays an important role [12], [31], [32].

In this paper a new Group Decision Support approach is proposed for Quality of Service (QoS) criteria analysis and weighting. In the first section a synthesis on objective and subjective criteria weighting methods is presented. In the second section a Group Decision Support approach for
QoS criteria weighting is proposed. A stepwise algorithm for this proposed approach is presented. Then the approach is applied on a case study for seven experts, eight QoS criteria and ten CSPs. An analysis of the causal relations and the degree of influence between QoS criteria is presented.

\section{Criteria Weighting Methods}

In MCDM approaches, weights of criteria reflect the relative importance of criteria in the decision making process. The most critical input to most MCDM methods is the assignment of criteria weights which can be based on subjective, objective or a combination of weighting methods.

Subjective weighting methods are based on the experts' opinion while the emphasis of the objective methods is on the statistical evaluation of data provided by the decision matrix. Subjective weighting may be preferable since in most real problems, the expert's expertise and judgment should be taken into account. In the situations when such reliable subjective weights are difficult to obtain, the use of objective weights is useful [27]. Each of these methods has its own advantages and disadvantages. Due to the lack of experience, imprecise information, limited capability of the expert for analyzing and 
Table 1. Objective and subjective criteria weighting methods

\begin{tabular}{|c|c|c|c|}
\hline Criteria weighting method & Type & Year & References \\
\hline Entropy method (Shannon's entropy concept, Shannon method) & $\mathrm{O}$ & 1948 & {$[21] ;[42] ;[41]$} \\
\hline $\begin{array}{l}\text { Linear programming techniques for multidimensional analysis of } \\
\text { preference (LINMAP) }\end{array}$ & $\mathrm{O}$ & 1973 & {$[45] ;[28]$} \\
\hline Simple Multi-Attribute Rating Technique (SMART) & $\mathrm{S}$ & 1977 & {$[13]$} \\
\hline Analytical Hierarchy Process (AHP) & $\mathrm{S}$ & 1977 & [36]; [37]; [38];[10] \\
\hline Weighted Least-Square Method & $\mathrm{O}$ & 1979 & {$[6] ;[50]$} \\
\hline SMARTS & $\mathrm{S}$ & 1986 & [51] \\
\hline Delphi method & $\mathrm{S}$ & 1987 & [21] \\
\hline Simos'procedure and Revised SIMOS'procedure & $\mathrm{S}$ & 1990 & [43]; [15] \\
\hline SMARTER & $\mathrm{S}$ & 1994 & {$[5] ;[14]$} \\
\hline Criteria Importance through Intercriteria Correlations (CRITIC) & $\mathrm{O}$ & 1995 & [11] \\
\hline Analytical Network Process (ANP) & $\mathrm{S}$ & 2001 & [39] \\
\hline Superiority and inferiority ranking (SIR) & $\mathrm{S}$ & 2001 & [53] \\
\hline Digital Logic and Modified Digital Logic methods & $\mathrm{O}$ & 2007 & [9]; [2]; [3] \\
\hline Adjustable Mean Bars (AMB) Direct Weighting Method & $\mathrm{O}$ & 2007 & {$[2] ;[3]$} \\
\hline Extended SIMOS version for group decision making & $\mathrm{S}$ & 2008 & [42] \\
\hline Compromise Programming Technique & $\mathrm{O}$ & 2010 & [23] \\
\hline Step-Wise Weight Assessment Ratio Analysis (SWARA) & $\mathrm{S}$ & 2010 & [24]; [17] \\
\hline FActor RElationship (FARE) & $\mathrm{S}$ & 2011 & {$[18]$} \\
\hline Decision-Making Trial and Evaluation Laboratory (DEMATEL) & $\mathrm{S}$ & 2011 & [8]; [4]; [29] \\
\hline Correlation Coefficient and Standard Deviation (CCSD) & $\mathrm{O}$ & 2013 & [44] \\
\hline Projection Pursuit Algorithm & $\mathrm{O}$ & 2013 & [47] \\
\hline Principal Component Analysis & $\mathrm{O}$ & 2013 & [7] \\
\hline KEmeny Median Indicator Ranks Accordance (KEMIRA) & $\mathrm{S}$ & 2014 & {$[25]$} \\
\hline The best-worst method (BWM) & $\mathrm{S}$ & 2015 & [34]; [35] \\
\hline Mean square deviation method & $\mathrm{O}$ & 2016 & {$[48]$} \\
\hline $\begin{array}{l}\text { Integrated Determination of Objective CRIteria Weights, or (IDO- } \\
\text { CRIW) }\end{array}$ & $\mathrm{S}$ & 2016 & {$[54] ;[30]$} \\
\hline Criteria Impact LOSs (CILOS) & $\mathrm{S}$ & 2017 & [46] \\
\hline Extended Stepwise Weight Assessment Ratio Analysis (SWARA) & $\mathrm{S}$ & 2017 & [55]; [46] \\
\hline Bayes Approach & $\mathrm{O}$ & 2018 & {$[49]$} \\
\hline
\end{tabular}

Objective weighting method - O; Subjective weighting method - S

correlating criteria, sometimes the expert may not be able to assign precise weights to criteria.

On the other side the objective methods do not benefit from the expertise and experience of the experts [3]. Subjective or objective weighting methods are used in many MCDM problems. Examples of objective and subjective weighting methods are presented in Table 1.

There is not a "best" weighting method. Each method has its advantages and its drawbacks. That is why, some researchers such as [22], [52], [3] highly recommend combinative weighting methods to account for both types of subjective and objective weighting and arrive at a single, aggregated set of criteria weights.

\section{A Group Decision Support Approach for QoS Criteria Weighting}

The problem is to determine the QoS criteria weights used in selection of a CSP. To solve this problem a group decision support approach is proposed based on a combination of subjective weighting DEMATEL method and objective weighting Shannon method. We have chosen the 
DEMATEL method because, besides calculating the criteria weights it also determines the causal relationship and the degree of influence between the criteria. We have chosen the Shannon method because it is a classic method that is widely used to calculate weights. The combined method takes into account both the matrix of influential relationships between the criteria (the DEMATEL method) and the decision matrix criteria alternatives (Shannon method).

The DEMATEL method was developed by the Science and Human Affairs Program of the Battelle Memorial Institute of Geneva between 1972 and 1976. It takes into account the subjective evaluation of experts and solves complex and interrelated problems [16]. The aim of DEMATEL is to reveal direct/indirect causal relations (dependencies) among system variables.

The DEMATEL method compares the interaction relationship between variables and uses a matrix to calculate the direct and indirect causal relationships and the degree of influence between variables, especially using the Influential Network Relation Map (INRM) to express the causal relationships and the degree of influence between variables [19]. The DEMATEL method can solve problems visually and can isolate the related variables into cause and effect groups in order to improve the understanding of the causal relationships among these variables [26], [33].

One of the classic objective weighting method is the Shannon entropy method [1], [41]. The concept of Shannon's entropy has an important role in information theory and it is used as a general measure of uncertainty [27]. In MADM the entropy weight describes how much different alternatives are closed one another with respect to a certain criterion. The greater the value of the entropy the smaller the entropy weight is, then the smaller the differences between different alternatives are in this specific criterion, the less information the specific criterion provides, and the less important this criterion becomes in the decision making process [50].

The Group Decision Support approach steps are:

Step 1. A set of $q$ cloud experts select a set of $m$ important QoS criteria to be evaluated and analyzed in the CSP selection.

\section{DEMATEL method.}

Step 2. The scale for measuring the relationships between QoS criteria is considered across five levels. The scores $0,1,2,3$, and 4 represent 'no influence,' 'low influence,' 'medium influence,' 'high influence,' and 'very high influence,' respectively. For the QoS criteria selection a questionnaire for evaluation is defined.

Step 3. The cloud experts are asked to make sets of comparisons between QoS criteria from the selected set. For each cloud expert $r$ from the set of $q$ cloud experts an initial direct relation/ influence $m \times m$ matrix $A^{(r)}=\left(a_{j}^{(r)}\right)$, is obtained. The element $a_{i j}^{(r)}$ denotes evaluation of the $r$-th cloud expert to the degree to which the $i$-th QoS criterion influences the $j$-th QoS criterion.

Step 4. From the set of $q$ direct relation/ influence matrices of cloud experts, it is calculated a $m \times m$ average matrix $A=\left(a_{i j}\right)$, each element $a_{i j}$ being the arithmetic mean of the corresponding elements in the $q$ direct matrices of the cloud experts. That is: $A=(1 / q) \times\left(A^{(1)}+A^{(2)}+\ldots+A^{(q)}\right)$

Step 5. Build the $m \times m$ normalized direct relation matrix $N$. $N$ is obtained by normalizing matrix $A$. In $N$ all principal diagonal elements are equal to zero:

$s=\max \left(\max _{1 \leq i \leq m}\left(\sum_{j=1}^{m} a_{j}\right), \max _{1 \leq j \leq m}\left(\sum_{i=1}^{m} a_{j}\right)\right)$,

$N=A / s$

Step 6: Build the $m \times m$ QoS criteria total influence matrix $T=\left(t_{i j}\right)$ as: $T=N(I-N)^{-1}$ where $I$ is an identity matrix.

Note that: $\lim _{h \rightarrow \infty} N^{h}=\left(0_{m \times m}\right)$.

Step 7. Construct the QoS criteria Influential Network Relation Map (INRM) with the help of the vectors $\mathbf{y}=\left(y_{1}, y_{2}, \ldots, y_{n}\right)$ and $\mathbf{z}=\left(z_{1}, z_{2}, \ldots, z_{n}\right)$ :

$z_{i}=\sum_{j=1}^{m} t_{i j}, \quad i=1,2, \ldots, m$,

$y_{j}=\sum_{i=1}^{m} t_{i j}, \quad j=1,2, \ldots, m$

The vector $\mathbf{z}$ is the sum of all columns vectors of $T$. The $i$-th entry of $\mathbf{z}$ represents the degree to which the $i$-th QoS criterion influences all other QoS criteria. The vector $\mathbf{y}$ is the sum of all vector rows of $T$. 
The $j$-th entry of $\mathbf{y}$ represents the degree to which the $j$-th QoS criteria are influenced by all other QoS criteria.

The $\operatorname{sum}\left(z_{i}+y_{i}\right)$ represents the degree of influence between the $i$-th criterion and the other QoS criteria.

The difference $\left(z_{i}-y_{i}\right)$ represents the degree of causality between the $i$-th criterion and the other QoS criteria.

If $\left(z_{i}-y_{i}\right)$ is positive, then the $i$-th QoS criterion influences other QoS criteria and shall be attributed as a cause type. If $\left(z_{i}-y_{i}\right)$ is negative, then the $i$-th QoS criterion is influenced by other QoS criteria and shall be attributed as an effect type. If $\left(z_{i}-y_{i}\right)$ has a negative value and the value of $\left(z_{i}+y_{i}\right)$ is very small, it means that the $i$-th QoS criterion is more independent, and there are fewer factors which will impact the QoS criterion. When $\left(z_{i}-y_{i}\right)$ has a positive value and the value of $\left(z_{i}+y_{i}\right)$ is very small, it means that the $i$-th QoS criterion is also independent, and can impact a few other QoS criteria.

If $\left(z_{i}-y_{i}\right)$ has a negative value and the value of $\left(z_{i}+y_{i}\right)$ is very large, it means that QoS criterion $i$ is the core problem required to be solved. When $\left(z_{i}-y_{i}\right)$ has a positive value and the value of $\left(z_{i}+y_{i}\right)$ is large, it means that QoS criterion $i$ is the driving factor of solving the core problem, and it shall be listed as priority.

Step 8. Build the DEMATEL QoS criteria weights as:

$$
w_{i}^{D}=\left(z_{i}+y_{i}\right) / \sum_{j=1}^{m}\left(z_{j}+y_{j}\right), \quad i=1,2, \ldots, m
$$

Criteria weights can still be obtained using the DANP method which is a combination of the DEMATEL method and the Analytic Network Process (ANP) method.

\section{Shannon method.}

Step 9. A selection of a set with $n$ CSPs, to be evaluated, is made. The cloud experts are asked to make CSPs assessments using QoS criteria. For each cloud expert $r$ from the set of $q$ cloud experts a $n \times m$ decision matrix $E^{(r)}=\left(e_{j}^{(r)}\right)$, is obtained. The element $e_{i j}^{(r)}$ denotes evaluation of $r$-th cloud expert of the $i$-th CSP for $j$-th QoS criterion.
Step 10. From the set of $q$ decision matrices associated with cloud experts, is calculated an $n \times m$ average decision matrix $E=\left(e_{i j}\right)$, each element $e_{i j}$ is calculated as arithmetic mean of the corresponding element in the set of $q$ decision matrices of the cloud experts. That is:

$$
E=(1 / q) \times\left(E^{(1)}+E^{(2)}+\ldots+E^{(q)}\right)
$$

Step 11. The normalized decision matrix is calculated:

$$
P=\left(p_{i j}^{w}\right) \quad p_{j}^{w}=e_{j} / \sum_{k=1}^{n} e_{k}, \quad i=1,2, \ldots, n
$$

Then $e_{j}^{w}$ is calculated:

$e_{j}^{w}=-\frac{\sum_{i=1}^{n} p_{j}^{w} \ln \left(p_{j}^{w}\right)}{\ln (n)}, 0 \leq e_{j}^{w} \leq 1$

Define the criteria weight based on the entropy concept:

$w_{j}^{o}=\frac{\left(1-e_{j}^{w}\right)}{\sum_{k=1}^{n}\left(1-e_{k}^{w}\right)}, \quad j=1,2, \ldots, m$

Step 12. From a combination of DEMATEL weights (step 8) and entropy weights (step 11), the final form of the criteria weights is calculated:

$w_{j}=\frac{w_{j}^{D * w_{j}^{o}}}{\sum_{k=1}^{m} w_{j}^{D * w_{j}^{o}}}, \quad j=1,2, \ldots, m$

The group decision support approach for QoS criteria weighting is illustrated in Figure 1.

\section{Group Decision Support Approach - Case Study}

Eight QoS criteria for the CSP selection are chosen by seven experts in the field of Cloud Computing. The QoS criteria are: Availability, Security, VM Cost, Service Response Time, Data and Storage Cost, Accountability, Support Level and Memory Level. The selected QoS criteria are of two types: quantitative and qualitative criteria. The quantitative criteria are: VM Cost, Service Response Time and Data and Storage Cost. The qualitative criteria are: Availability, Security, Accountability, Support Level and Memory Level. 


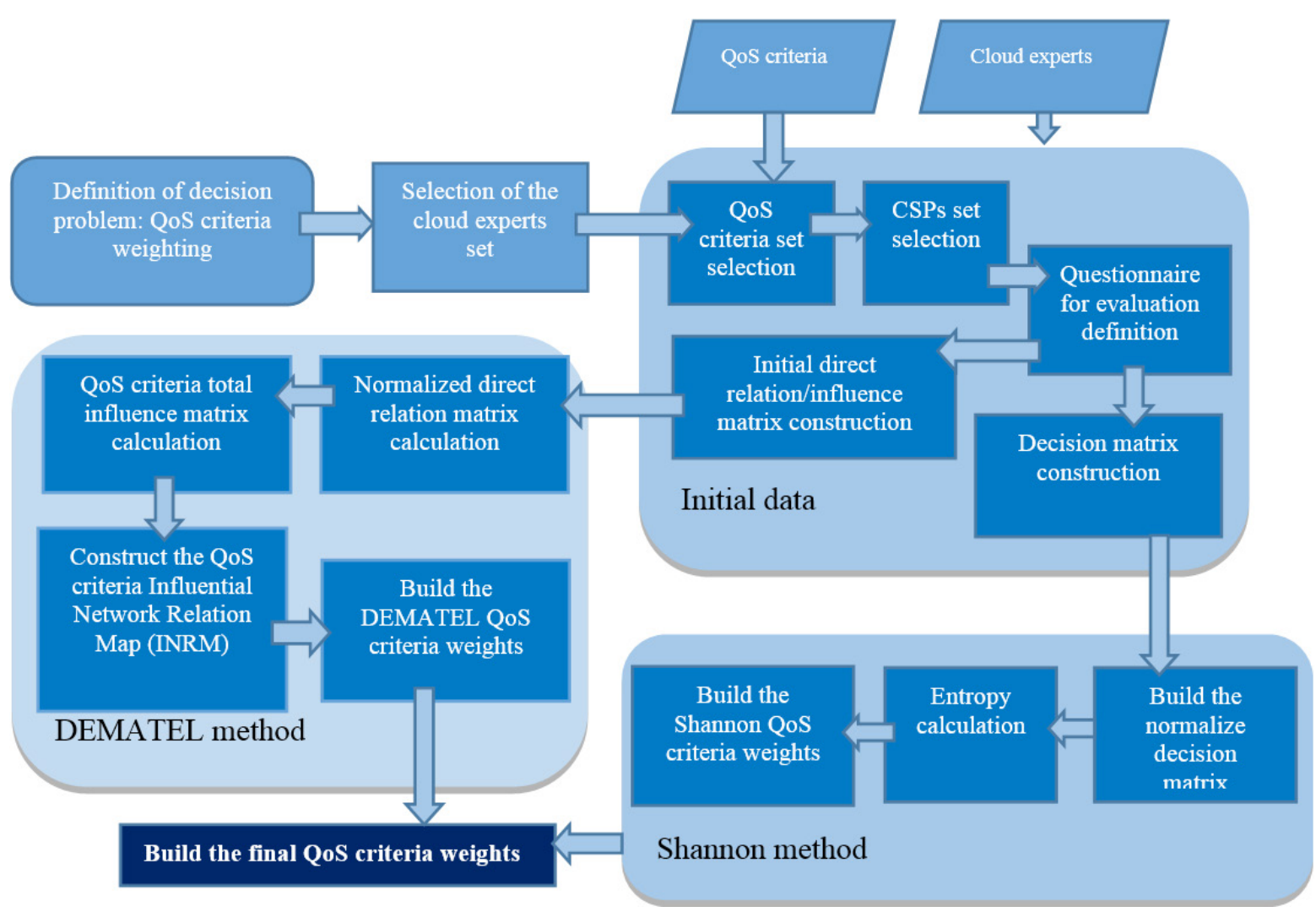

Figure 1. The Group Decision Support approach for QoS criteria weighting

Table 2. QoS criteria

\begin{tabular}{|c|c|c|c|c|c|}
\hline $\begin{array}{l}\text { Nr. } \\
\text { crt. }\end{array}$ & QoS criteria & Symbol & Description & $\begin{array}{l}\text { Criteria } \\
\text { Type }\end{array}$ & $\begin{array}{c}\text { Measure } \\
\text { unit }\end{array}$ \\
\hline 1 & Availability & $\mathrm{C} 1$ & $\begin{array}{l}\text { Availability indicates the time during the ser- } \\
\text { vice provider guarantees availability of data } \\
\text { and services for the user. }\end{array}$ & $\max$ & $0-10$ \\
\hline 2 & Security & $\mathrm{C} 2$ & $\begin{array}{l}\text { Security indicate the effectiveness of a CSP in } \\
\text { controlling access to services, service data and } \\
\text { physical facilities from which services are pro- } \\
\text { vided. }\end{array}$ & $\max$ & $0-10$ \\
\hline 3 & VM Cost & $\mathrm{C} 3$ & The Cost of using Virtual Machines & $\min$ & $\$ / \mathrm{h}$ \\
\hline 4 & $\begin{array}{l}\text { Service Re- } \\
\text { sponse Time }\end{array}$ & $\mathrm{C} 4$ & $\begin{array}{l}\text { The service response time is defined as the time } \\
\text { it takes for any workload to place a request for } \\
\text { work on the virtual environment and for the } \\
\text { virtual environment to complete the request. }\end{array}$ & $\min$ & Sec. \\
\hline 5 & $\begin{array}{l}\text { Data and Stor- } \\
\text { age Cost }\end{array}$ & C5 & $\begin{array}{l}\text { The cost of storage and maintaining data in } \\
\text { cloud }\end{array}$ & $\min$ & $\$ / \mathrm{m}$ \\
\hline 6 & Accountability & C6 & $\begin{array}{l}\text { Accountability is used to measure the proper- } \\
\text { ties related to a CSP. These properties may be } \\
\text { independent of the service being provided. }\end{array}$ & $\max$ & $0-10$ \\
\hline 7 & Support Level & $\mathrm{C} 7$ & $\begin{array}{l}\text { The level of support in using the service pro- } \\
\text { vided by the CSP. Support level is the extent } \\
\text { of technical assistance provided for CSP to its } \\
\text { customers. }\end{array}$ & $\max$ & $0-10$ \\
\hline 8 & Memory Level & $\mathrm{C} 8$ & $\begin{array}{l}\text { Cloud services demand a large amount of } \\
\text { memory. Memory size requirements increase if } \\
\text { the number of files increases. }\end{array}$ & $\max$ & $0-10$ \\
\hline
\end{tabular}


For the QoS criteria evaluation a questionnaire that includes two sections is defined. The first section includes the evaluation of the eight QoS criteria. The expert's evaluation is made based on a DEMATEL method measure scale. The second section explains the QoS criteria selection. The eight QoS criteria considered for evaluation and analysis are presented in Table 2.

The seven experts are asked to make sets of comparisons between QoS criteria based on the DEMATEL measure scales. The initial direct relation/influence matrix $A=\left(a_{\ddot{j}}\right)$ is obtained. Each array $a_{i j}$ element is the arithmetic mean of the corresponding elements in the seven direct matrices of the experts. The initial direct relation/ influence matrix $\mathrm{A}$ is presented in Table 3. The total influence matrix (see Table 4) and the QoS criteria INRM (see Figure 2 and Table 5) are calculated.

The arithmetic mean of the arrays of the vector $z-y$ is 0 and the arithmetic mean of the arrays of the vector $z^{+}+y$ is 3.138 . Starting from the means 0 and 3.138, the horizontal and vertical lines, divide the INRM into four quadrants, as it is shown in Figure 2. The horizontal axis $z^{+} y$ represents the prominence and the vertical axis z-y represents the relation. According to the analysis of Figure 2, the high prominence and relation in first quadrant are represented by $\mathrm{C} 1$ (Availability), C2 (Security) and C6 (Accountability). These QoS criteria have the highest interaction influence degree with other

Table 3. The initial direct relation/influence matrix A

\begin{tabular}{|c|c|c|c|c|c|c|c|c|}
\hline QoS criteria & C1 & C2 & C3 & C4 & C5 & C6 & C7 & C8 \\
\hline C1 & 0 & 4.429 & 4.857 & 4 & 2.857 & 4.143 & 4 & 4.143 \\
\hline C2 & 2.857 & 0 & 4 & 3 & 5 & 4 & 2 & 2 \\
\hline C3 & 3 & 3.429 & 0 & 3.857 & 1.429 & 1 & 1 & 2 \\
\hline C4 & 2.857 & 2.857 & 2 & 0 & 0.429 & 2 & 3 & 0.857 \\
\hline C5 & 2 & 4 & 4.143 & 2.143 & 0 & 1.286 & 0 & 2.571 \\
\hline C6 & 1.857 & 2.143 & 2.714 & 4.143 & 1.857 & 0 & 5 & 2 \\
\hline C7 & 2.857 & 1 & 2.286 & 3 & 0.429 & 3.143 & 0 & 1.857 \\
\hline C8 & 0.857 & 1.571 & 0.429 & 0 & 1.143 & 1 & 2 & 0 \\
\hline
\end{tabular}

Table 4. Total influence matrix $T$

\begin{tabular}{|c|c|c|c|c|c|c|c|c|}
\hline $\begin{array}{c}\text { QoS } \\
\text { criteria }\end{array}$ & C1 & C2 & C3 & C4 & C5 & C6 & C7 & C8 \\
\hline C1 & 0.189 & 0.352 & 0.374 & 0.354 & 0.243 & 0.318 & 0.320 & 0.300 \\
\hline C2 & 0.249 & 0.187 & 0.319 & 0.290 & 0.284 & 0.280 & 0.225 & 0.211 \\
\hline C3 & 0.211 & 0.243 & 0.139 & 0.259 & 0.144 & 0.153 & 0.153 & 0.170 \\
\hline C4 & 0.199 & 0.211 & 0.194 & 0.132 & 0.104 & 0.177 & 0.209 & 0.127 \\
\hline C5 & 0.181 & 0.263 & 0.270 & 0.208 & 0.101 & 0.157 & 0.116 & 0.188 \\
\hline C6 & 0.198 & 0.218 & 0.243 & 0.293 & 0.161 & 0.135 & 0.295 & 0.184 \\
\hline C7 & 0.196 & 0.154 & 0.197 & 0.226 & 0.097 & 0.206 & 0.116 & 0.156 \\
\hline C8 & 0.081 & 0.109 & 0.079 & 0.065 & 0.082 & 0.088 & 0.118 & 0.048 \\
\hline
\end{tabular}

Table 5. The elements of INRM

\begin{tabular}{|c|c|c|c|c|c|c|c|c|}
\hline QoS criteria & C1 & C2 & C3 & C4 & C5 & C6 & C7 & C8 \\
\hline z & 2.449 & 2.046 & 1.472 & 1.354 & 1.483 & 1.727 & 1.349 & 0.671 \\
\hline $\mathrm{y}$ & 1.505 & 1.737 & 1.816 & 1.826 & 1.216 & 1.514 & 1.552 & 1.385 \\
\hline z-y & 0.944 & 0.309 & -0.344 & -0.472 & 0.268 & 0.213 & -0.203 & -0.714 \\
\hline Impact & Cause & Cause & Effect & Effect & Cause & Cause & Effect & Effect \\
\hline z+y & 3.954 & 3.783 & 3.288 & 3.180 & 2.699 & 3.241 & 2.901 & 2.056 \\
\hline $\begin{array}{c}\text { DEMATEL QoS } \\
\text { Criteria weights }\end{array}$ & 0.158 & 0.151 & 0.131 & 0.127 & 0.108 & 0.129 & 0.116 & 0.082 \\
\hline
\end{tabular}


Table 6. The decision matrix $E$

\begin{tabular}{|c|c|c|c|c|c|c|c|c|}
\hline QoS criteria & C1 & C2 & C3 & C4 & C5 & C6 & C7 & C8 \\
\hline CSP1 & 9.3 & 8 & 0.76 & 120 & 23.7 & 7 & 8 & 9 \\
\hline CSP2 & 9 & 9 & 0.55 & 150 & 24.5 & 6 & 9.5 & 8 \\
\hline CSP3 & 8.2 & 8.5 & 0.65 & 125 & 27.5 & 8 & 9 & 10 \\
\hline CSP4 & 9.1 & 8.6 & 0.34 & 180 & 23.5 & 5 & 8.5 & 9.5 \\
\hline CSP5 & 9.5 & 8 & 0.63 & 90 & 25.5 & 7 & 8 & 9 \\
\hline CSP6 & 7.3 & 8.7 & 0.66 & 160 & 26 & 7 & 8.5 & 10 \\
\hline CSP7 & 8.1 & 9.3 & 0.54 & 123 & 25 & 8 & 9 & 9.5 \\
\hline CSP8 & 9.2 & 9 & 0.74 & 126 & 21.5 & 6 & 9.5 & 8.5 \\
\hline CSP9 & 8.2 & 8.2 & 0.47 & 185 & 24.8 & 5 & 9 & 8 \\
\hline CSP10 & 7.5 & 9.5 & 0.43 & 145 & 25.1 & 7 & 9.5 & 9 \\
\hline
\end{tabular}

Table 7. Final QoS criteria weights

\begin{tabular}{|c|c|c|c|}
\hline QoS criteria & $\begin{array}{c}\text { DEMATEL QoS Criteria } \\
\text { weights }\end{array}$ & $\begin{array}{c}\text { Shannon QoS } \\
\text { Criteria weights }\end{array}$ & $\begin{array}{c}\text { Final QoS Crite- } \\
\text { ria weights }\end{array}$ \\
\hline C1 & 0.1575 & 0.0543 & 0.0668 \\
\hline C2 & 0.1507 & 0.0232 & 0.0272 \\
\hline C3 & 0.1310 & 0.3699 & 0.3774 \\
\hline C4 & 0.1267 & 0.2831 & 0.2801 \\
\hline C5 & 0.1075 & 0.0272 & 0.0229 \\
\hline C6 & 0.1291 & 0.1735 & 0.1743 \\
\hline C7 & 0.1156 & 0.0276 & 0.0250 \\
\hline C8 & 0.0819 & 0.0413 & 0.0264 \\
\hline
\end{tabular}

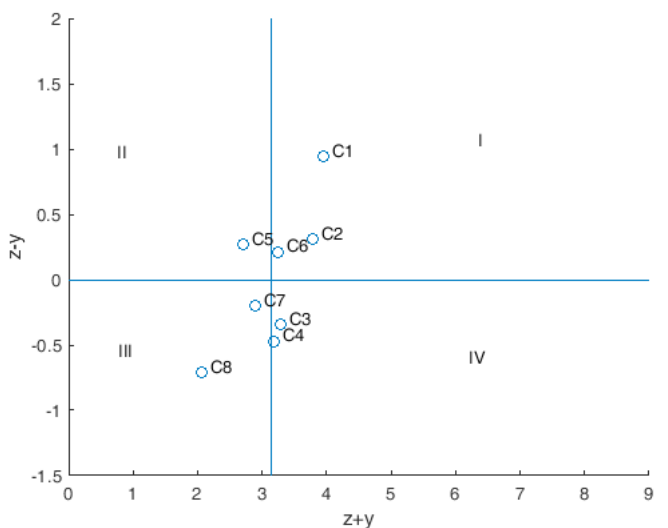

Figure 2. Influential Network Relation Map - INRM

QoS criteria, and thus, they are the driving factors. The fourth quadrant has high prominence but low relation. The criteria in the fourth quadrant are C3 (VM Cost) and C4 (Service Response Time) which means that these criteria are impacted by other conditions.

Other QoS criteria, C8 (Memory) and C7 (Support Level) are in the third quadrant, with low prominence and relation. However, C7 criterion is very close to the fourth quadrant. C5 (Data and Storage Cost) criterion is in the second quadrant (with low prominence but high relation).

Ten CSPs are selected for evaluation. The decision matrix of cloud experts $E$ is presented in Table 6 .

The normalized decision matrix and the Shannon QoS criteria weights are calculated. Then the final form of the QoS criteria weights are calculated according to step 12 (see Table 7).

The criterion with the highest weight in the DEMATEL subjective weighting method is $\mathrm{C} 1$ - Availability and the second criterion is C2 Security. The criterion with the highest weight in the Shannon objective weighting method is C3 - VM Cost and the second is C4 - Service Response Time.

The method that combines the weights obtained by the DEMATEL subjective method with the weights obtained by the Shannon objective method considers that the highest weight has the criterion C3 - VM Cost. Note that the final criteria weights are close to the Shannon criteria 
and the difference between the DEMATEL criteria weights and the Shannon criteria weights is lower than the difference between the final criteria weights and Shannon criteria weights.

\section{Conclusion}

The present paper calculates the cloud QoS criteria weights based on a combination of the DEMATEL subjective weighting method and the Shannon objective weighting method. The causal relationships and the degree of influence

\section{REFERENCES}

1. Andreica, M. E., Dobre, I., Andreica, M. I. \& Resteanu, C. (2010). A New Portfolio Selection Method Based on Interval Data, Studies in Informatics and Control, 19(3), 253-262.

2. Ardakani, M. A. (2007). Enhancing impact characterization and Multi-Criteria Design Optimization of glass fiber reinforced polypropylene laminates, Doctoral thesis, University of Tehran.

3. Ardakani, M. A., Milani, A., Yannacopoulos, S. \& Shokouhi, G. (2016). On the effect of subjective, objective and combinative weighting in multiple criteria decision making: A case study on impact optimization of composites, Expert Systems With Applications, 46, 426-438.

4. Baykasoglu,A., Kaplanoglu, V., Durmusoglu, Z. D. U. \& Sahin, C. (2013). Integrating Fuzzy DEMATEL and Fuzzy Hierarchical TOPSIS Methods for Truck Selection, Expert Systems with Applications, 40, 899-907.

5. Barron, F. H. \& Barrett, B. E. (1996). Decision quality using ranked attribute weights, Management Science, 42, 1515-1523.

6. Chu, A. T. W., Kalaba, R. E. \& Spingarn, K. (1979). A comparison of two methods for determining the weights of belonging to fuzzy sets, Journal of Optimization Theory and Applications, 27(4), 531-538.

7. Croux, C., Filzmoser, P. \& Fritz, H. (2013). Robust sparse principal component analysis, Technometrics, 55, 202-214.

8. Dalalah, D., Hajaneh, M. \& Batieha, F. (2011). A Fuzzy Multi-criteria Decision between criteria from a set of QoS criteria are investigated with the help of the DEMATEL method. The research is based on the opinions of a set of cloud experts.

The analysis provides important information to CSPs for promoting their cloud services and a better understanding of the most important QoS criteria that influence the customer's decisions in the adoption of cloud services. Consequently CSPs can develop a more focused strategy for meeting customer demands.

Making Model for Supplier Selection, Expert Systems with Applications, 38, 8384-8391.

9. Dehghan-Manshadi, B., Mahmudi, H., Abedian, A. \& Mahmudi, R. (2007). A novel method for materials selection in mechanical design: combination of nonlinear normalization and a modified digital logic method, Materials \& Design, 28(1), 8-15.

10. Deng, X., Hu, Y., Deng, Y. \& Mahadevan, S. (2014). Supplier selection using AHP methodology extended by D numbers, Expert System with Applications, 41(1), 156-167.

11. Diakoulaki, D., Mavrotas, G. \&Papayannakis, L. (1995). Determining objective weights in multiple criteria problems: the critic method, Computers \& Operations Research, 22(7), 763-770.

12. Dumitrache, M., Sandu, I. E. \& Barbu, D. C. (2017). An Integrated Cloud Computing Solution for Romanian Public-Sector Entities: ICIPRO Project, Studies in Informatics and Control, 26(4), 481-487.

13. Edwards, W. (1977). How to use multi attribute utility measurement for social decisionmaking, IEEE Transactions on Systems, Man, and Cybernetics, 7(5), 326-340.

14. Edwards, W. \& Barron, F. H. (1994). SMARTS and SMARTER - improved simple methods for multi attribute utility measurement, Organizational Behaviour and Human Decision Processes, 60, 306-325.

15. Figueira, J. \& Roy, B. (2002). Determining the weights of criteria in the ELECTRE type methods with a revised Simos' procedure, 
European Journal of Operational Research, 139, 317-326.

16. Gabus, A. \& Fontela, E. (1973). Perceptions of the world problematique: communication procedure, communicating with those bearing collective responsibility, DEMATEL Report No.1. Battelle Geneva Research Center, Switzerland.

17. Ghorshi Nezhad, M. R., Hashemkhani Zolfani, S., Moztarzadeh, F., Zavadskas, E. K. \& Bahrami, M. (2015). Planning the priority of high tech industries based on SWARA-WASPAS methodology: the case of the nanotechnology industry in Iran, Economic Research Ekonomska Istraživanja, 28(1), 1111-1137.

18. Ginevicius, R. (2011). A new determining method for the criteria weights in multicriteria evaluation, International Journal of Information Technology \& Decision Making, 10(6),1067-1095.

19. Gölcük, I. \& Baykasoglu, A. (2016). An analysis of DEMATEL approaches for criteria interaction handling within ANP, Expert Systems with Applications, 46, 346-366.

20. Hwang, C. L. \& Lin, M. J. (1987). Group decision making under multiple criteria: methods and applications. SpringerVerlag, Berlin.

21. Hwang, C. L. \& Yoon, K. (1981). Multiple attribute decision making: methods and applications. Springer-Verlag.

22. Jiménez, A., Ríos-Insua, S. \& Mateos, A. (2006). Using a Combination of Weighting Methods. in Multiattribute Decision-Making. In: Haasis, H. D., Kopfer, H. \& Schönberger, J. (eds), Operations Research Proceedings. Springer, Berlin, Heidelberg.

23. Kao, C. (2010). Weight determination for consistently ranking alternatives in multiple criteria decision analysis, Applied Mathematical Modelling, 34, 1779-1787.

24. Kersuliene, V., Zavadskas, E. K. \& Turskis, Z. (2010). Selection of rational dispute resolution method by applying new step wise weight assessment ratio analysis (SWARA), Journal of Business Economics and Management, 11(2), 243-258.

25. Krylovas, A., Zavadskas, E., Kosareva, N. \& Dadelo, S. (2014). New KEMIRA method for determining criteria priority and weights in solving MCDM problem, International Journal of Information Technology and Decision Making, 13, 1119-1133.

26. Lee, Y. C., Li, M. L., Yen, T. M. \& Huang, T. H. (2010). Analysis of adopting an integrated DEcision MAking Trial and Evaluation Laboratory on a technology acceptance model, Expert Systems with Applications, 37, 1745-1754.

27. Lotfi, F. H. \& Fallahnejad, R. (2010). Imprecise Shannon's Entropy and Multi Attribute Decision Making, Entropy, 12, 53-62.

28. Ma, J., Fan, Z. P. \& Huang, L. H. (1999). A subjective and objective integrated approach to determine attribute weights, European Journal of Operational Research, 112(2), 397-404.

29. Patil, S. K. \& Kant, R. (2014), A Hybrid Approach Based on Fuzzy DEMATEL and FMCDM to Predict Success of Knowledge Management Adoption in Supply Chain, Applied Soft Computing, 18, 126-135.

30. Podvezko, V., Kildienè, S. \& Zavadskas, E. K. (2017). Assessing the performance of the construction sectors in the Baltic states and Poland, Panoeconomicus, 64(4), 493-512.

31. Rădulescu, C. Z. \& Rădulescu, I. (2017). An Extended TOPSIS Approach for Ranking Cloud Service Providers, Studies in Informatics and Control, 26(2), 183-192.

32. Rădulescu, C. Z., Rădulescu, D. M. \& Harţescu, F. (2017). A cloud service providers ranking approach, based on SAW and modified TOPSIS methods. In Proceedings of the $16^{\text {th }}$ International Conference on Informatics in Economy (IE 2017) (pp. 7-12).

33. Resteanu, C., Popescu, C., Popescu, C. \& Popescu, M. E. (2016). A Scientometric Method to Evaluate the Academic Research Performance, Studies in Informatics and Control, 25(4), 433-444.

34. Rezaei, J. (2015). Best-worst multi-criteria decision-making method, Omega, 53, 49-57.

35. Rezaei, J. (2016). Best-worst multi-criteria decision-making method: Some properties and a linear model, Omega, 64, 126-130. 
36. Saaty, T. L. (1977). A scaling method for priorities in hierarchical structures, Journal of mathematical psychology, 15(3), 234-281.

37. Saaty, T. L. (1980). The Analytic Hierarchy Process. McGraw-Hill Press, NewYork.

38. Saaty, T. L. (1990). How to make a decision: the Analytic Hierarchy Process, European Journal of Operational Research, 48(1), 9-26.

39. Saaty, T. L. (2001). Decision making with dependence and feedback: the analytic network process. RWS Publications, Pittsburgh.

40. Shanian, A., Milani, A. S., Carson, C. \& Abeyaratne, R. C. (2008). A new application of ELECTRE III and revised Simos'procedure for group material selection under weighting uncertainty, Knowledge-Based Systems, 21(7), 709-720.

41. Shannon, C. E. \& Weaver, W. (1963). The Mathematical Theory of Communication. The University of Illinois Press, Urbana.

42. Shannon, C. E. (1948). A note on the concept of entropy, Bell System Technical Journal, $27,379-423$.

43. Simos,J.(1990).L'évaluationenvironnementale: Un processus cognitive négocié, Thèse de doctorat, DGF-EPFL, Lausanne.

44. Singh, R. K. \& Benyoucef, L. (2013). A consensus based group decision making methodology for strategic selection problems of supply chain coordination, Engineering Applications of Artificial Intelligence, 26, 122-134.

45. Srinivasan, V. \& Shocker, A. D. (1973). Linear programming techniques for multidimensional analysis of preferences, Psychometrika, 38(3), 337-369.

46. Stanujkic, D., Zavadskas, E., Karabasevic, D., Smarandache, F. \& Turskis, Z. (2017). The use of the pivot pairwise relative criteria importance assessment method for determining the weights of criteria, Romanian Journal of Economic Forecasting, 20, 116-133.

47. Su, H., Qin, P. \& Qin, Z. (2013). A Method for Evaluating Sea Dike Safety, Water Resources Management, 27, 5157-5170.

48. Subramanian, T. \& Savarimuthu, N. (2016). Application based brokering algorithm for optimal resource provisioning in multiple heterogeneous clouds, Vietnam Journal of Computer Science, 3, 57-70.

49. Vinogradova, I., Podvezko, V. \& Zavadskas, E. (2018). The Recalculation of the Weights of Criteria in MCDM Methods Using the Bayes Approach, Symmetry, 10(6), 205.

50. Wang, T. C. \& Lee, H. D. (2009). Developing a fuzzy TOPSIS approach based on subjective weights and objective weights, Expert Systems with Applications, 36, 8980-8985.

51. Von Winterfeldt, D. \& Edwards, W. (1986). Decision analysis and behavioral research. Cambridge University Press, Cambridge.

52. Yin, F., Lu, L., Chai, J. \& Yang, Y. (2016). Combination Weighting Method Based on Maximizing Deviations and Normalized Constraint Condition, International Journal of Security and Its Applications, 10(2), 39-50.

53. Xu, X. (2001). The SIR method: a superiority and inferiority ranking method for multiple criteria decision making, European Journal of Operational Research, 131, 587-602.

54. Zavadskas, E. K. \& Podvezko, V. (2016). Integrated Determination of Objective Criteria Weights in MCDM, International Journal of Information Technology \& Decision Making, 15(2), 267-283.

55. Zolfani, S., Yazdani, M. \& Zavadskas, E. (2018). An extended Stepwise Weight Assessment Ratio Analysis (SWARA) method for improving criteria prioritization process, Soft Computing. <https://doi. org/10.1007/s00500-018-3092-2>. 